(A) Check for updates

Cite this: Food Funct., 2018, 9, 3166

\title{
Incorporation of tocopherol-rich extracts from mushroom mycelia into yogurt
}

\author{
Chaima Bouzgarrou, $\uparrow^{a, b}$ Khira Amara, $\dagger^{a, b}$ Filipa S. Reis, ${ }^{a}$ João C. M. Barreira, (ID) \\ Fethia Skhiri, ${ }^{b}$ Noureddine Chatti, ${ }^{b}$ Anabela Martins, ${ }^{a}$ Lillian Barros (D) a and \\ Isabel C. F. R. Ferreira (D) *a
}

\begin{abstract}
Consumers are well-informed about food additives and it is likely that they prefer natural additives over their synthetic analogues. Antioxidants represent a major class of food preservatives, among which tocopherols stand out as one of the most important examples. Interestingly, these compounds are present in relevant amounts in the mycelia of in vitro cultured mushrooms. Accordingly, the mycelia from Ganoderma lucidum, Pleurotus ostreatus and Pleurotus eryngii were used as alternative sources of tocopherols. These extracts were incorporated into different yogurt formulations, which were further compared among each other and with yogurts containing commercial $\alpha$-tocopherol (E307), regarding their nutritional parameters, fatty acid profile and antioxidant activity. The proposed approach was validated as an effective functionalization strategy, particularly in the case of the G. lucidum mycelium, which showed the highest antioxidant potential, most likely as a result of its tocopherol profile. Furthermore, yogurts prepared with each mycelium extract allowed maintaining the nutritional properties observed in the "blank" yogurt formulation.
\end{abstract}

Received 13th March 2018,

Accepted 9th May 2018

DOI: $10.1039 / c 8 f \circ 00482 j$

rsc.li/food-function obvious choice as such an alternative. However, the mycelia remaining from mushroom production contain relevant levels of this vitamin, thereby raising its potential use as an inexpensive source of this bioactive compound. ${ }^{11}$

Owing to its biological effect, the inclusion of vitamin $\mathrm{E}$ in food products, where it is not naturally present, could represent an added-value to the product. Yogurt, for instance, has been recognized as having essential nutrients with health benefits, as well as non-nutritional components that prevent or delay the onset of chronic illnesses associated with age. ${ }^{12,13}$ However, it does not contain (except when mixed with nuts or seeds) vitamin E, so the supplementation with this component could increase its bioactive value, similar to what has been done in other functionalization approaches using hazelnut skins, ${ }^{14}$ chamomile, fennel ${ }^{15}$ and elmleaf blackberry. ${ }^{16}$

Herein, the mycelia of Pleurotus ostreatus (Jacq. ex Fr.) P. Kumm., Pleurotus eryngii (DC.) Quél., acknowledged as rich sources of bioactive phenols, polysaccharides ${ }^{17}$ and tocopherols, ${ }^{18}$ and Ganoderma lucidum (Curtis) P. Karst, also reported for different bioactivities, ${ }^{19-21}$ inclusively in its mycelium, ${ }^{22-25}$ were used as alternative tocopherol sources in yogurts.

The functionalized yogurts were further compared with a "blank" formulation (yogurt free of any additive), and with a fifth yogurt formulation incorporating synthetic $\alpha$-tocopherol (E307). The evaluated parameters included nutritional composition, free sugars, fatty acid profile and antioxidant activity and were evaluated in two different times: preparation day and 
after 7 days of storage. The main purpose was to verify the possibility of functionalizing yogurt through vitamin E incorporation without changing the main characteristics of this widely appreciated product.

\section{Materials and methods}

\section{Standards and reagents}

The solvents acetonitrile 99.9\%, $n$-hexane 95\% and ethyl acetate $99.8 \%$ were of high-performance liquid chromatography (HPLC) grade, obtained from Fisher Scientific (Lisbon, Portugal). Fatty acid methyl ester (FAME) reference standard mixture 37 (standard 47885-U) and other individual fatty acid isomers, individual sugars and Trolox (6-hydroxy-2,5,7,8-tetramethylchroman-2-carboxylic acid) were purchased from SigmaAldrich (St Louis, MO, USA). Racemic tocol $\left(50 \mathrm{mg} \mathrm{mL}^{-1}\right.$ ) as well as $\alpha-, \beta-, \gamma-$, and $\delta$-tocopherols were supplied from Matreya (Pleasant Gap, PA, USA). 2,2-Diphenyl-1-picrylhydrazyl (DPPH) was obtained from Alfa Aesar (Ward Hill, MA, USA). Methanol and all other chemicals and solvents were of analytical grade and purchased from common suppliers. Water was treated in a Milli-Q water purification system (TGI Pure Water Systems, Greenville, SC, USA).

\section{In vitro production of mycelia}

The mycelia of pre-established cultures of $P$. ostreatus, $P$. eryngii and $G$. lucidum were sub-cultured in order to maintain the quantities of inocula. necessary to develop the study. Briefly, small excised pieces from the previous cultures preserved in the Laboratory of Biology and Biotechnology were set to grow in new Petri dishes ( $9 \mathrm{~cm}$ diameter) with $\approx 10 \mathrm{~mL}$ of solid medium, and maintained in the dark in an in vitro culture chamber at $23 / 18{ }^{\circ} \mathrm{C}$ during the photoperiods of day and night (16/8 h), respectively. The most suitable growth conditions were tested by comparing three different solid culture media: (i) potato dextrose agar (PDA) pH 3.5 (39 $\left.\mathrm{g} \mathrm{L}^{-1}\right)$; (ii) Melin-Norkrans (MMN) pH $6.6\left(\mathrm{NaCl} 0.025 \mathrm{~g} \mathrm{~L}^{-1},\left(\mathrm{NH}_{4}\right) 2 \mathrm{HPO}_{4}\right.$ $0.250 \mathrm{~g} \mathrm{~L}^{-1}, \mathrm{KH}_{2} \mathrm{PO}_{4} 0.500 \mathrm{~g} \mathrm{~L}{ }^{-1} ; \mathrm{FeCl}_{3} 0.005 \mathrm{~g} \mathrm{~L} \mathrm{~L}^{-1}, \mathrm{CaCl}_{2}$ $0.050 \mathrm{~g} \mathrm{~L}^{-1}, \mathrm{MgSO}_{4} \cdot 7 \mathrm{H}_{2} \mathrm{O} 0.15 \mathrm{~g} \mathrm{~L}^{-1}$, thiamine $100 \mu \mathrm{g} \mathrm{mL} \mathrm{g}^{-1} \mathrm{~g}$ $\mathrm{L}^{-1}$, glucose $10.0 \mathrm{~g} \mathrm{~L}^{-1}$, agar $20 \mathrm{~g} \mathrm{~L}^{-1}$, malt extract $5 \mathrm{~g} \mathrm{~L}^{-1}$, casaminoacids $1 \mathrm{~g} \mathrm{~L}^{-1}$ ); and (iii) modified Melin-Norkrans (mMMN) pH $6.6\left(\mathrm{NaCl} 0.025 \mathrm{~g} \mathrm{~L}^{-1},\left(\mathrm{NH}_{4}\right) 2 \mathrm{HPO}_{4} 0.250 \mathrm{~g} \mathrm{~L}^{-1}\right.$, $\mathrm{KH}_{2} \mathrm{PO}_{4} 0.500 \mathrm{~g} \mathrm{~L}^{-1}, \mathrm{FeCl}_{3} 0.005 \mathrm{~g} \mathrm{~L}^{-1}, \mathrm{CaCl}_{2} 0.050 \mathrm{~g} \mathrm{~L}^{-1}$, $\mathrm{MgSO}_{4} \cdot 7 \mathrm{H}_{2} \mathrm{O} 0.15 \mathrm{~g} \mathrm{~L}^{-1}$, thiamine $100 \mu \mathrm{g} \mathrm{L} \mathrm{L}^{-1}$, glucose $10 \mathrm{~g} \mathrm{~L}^{-1}$, agar $20 \mathrm{~g} \mathrm{~L}^{-1}$ ). Seven days after the inoculation time, the radial growth was registered every 2 days until the plate area became fully covered with the mycelium. After reaching the maximum growth, the cultured Petri dishes were used for the inoculation of the species in the ideal culture medium, but in the liquid form, in order to obtain higher yields to perform the chemical assays. Since the best results for mycelium growth were obtained for the PDA medium, mycelia were sub-cultured in flasks $(250 \mathrm{~mL})$ with $30 \mathrm{~mL}$ of potato dextrose broth (PDB) $(\mathrm{pH}$ $\left.=5.1 \pm 0.2,27 \mathrm{~g} \mathrm{~L}^{-1}\right)$. Three excised fragments were inoculated in each flask of the culture medium. The flasks were held in the above-mentioned in vitro culture chamber, until enough biomass was obtained for the subsequent assays ( $\approx 32$ days). After that, mycelia were collected, weighed and then frozen and lyophilized (freeze 4.5 FreeZone model 7750031, Labconco, Kansas City, MO, USA). After lyophilisation, samples were weighed and then reduced to a fine powder (20 mesh), homogenized, and stored in a desiccator and protected from light until further analysis.

\section{Tocopherol extraction procedure}

Extracts were prepared following a previously described procedure. ${ }^{26}$ Before extraction, samples were added with butylhydroxytoluene (BHT, $100 \mu \mathrm{L})$ to avoid oxidation and spiked with tocol $(250 \mu \mathrm{L})$ as the internal standard (IS) for further chromatographic analysis. Samples $(\approx 500 \mathrm{mg})$ were extracted by vortex mixing with methanol $(4 \mathrm{~mL})$ for $1 \mathrm{~min}$; subsequently, hexane $(4 \mathrm{~mL})$ was added and the mixture was vortexed again for one additional minute. Finally, a saturated $\mathrm{NaCl}$ aqueous solution $(2 \mathrm{~mL})$ was added and the mixture was homogenized (1 min). After that, samples were centrifuged (5 min, 4000g), and the upper layer, corresponding to the hexane fraction, was transferred to a $25 \mathrm{~mL}$ amber vial. Samples were re-extracted twice with hexane and the combined extracts were taken to dryness under a nitrogen stream and stored at $-20^{\circ} \mathrm{C}$.

\section{Tocopherol analysis}

Tocopherol extracts were re-dissolved in $1 \mathrm{~mL}$ of $n$-hexane, dehydrated with anhydrous sodium sulfate, filtered $(0.22 \mu \mathrm{m}$ disposable LC filter disk) and transferred to an amber injection vial for chromatographic analysis. Tocopherol profiles were determined by HPLC (Smartline pump 1000, Knauer, Germany) connected to a FP-2020 fluorescence detector (using $290 \mathrm{~nm}$ and emission at $330 \mathrm{~nm}$, Jasco, Japan), following a previously optimized procedure. ${ }^{26}$ Separation was accomplished at $35{ }^{\circ} \mathrm{C}$ using a normal-phase Polyamide II column $(250 \times$ $4.6 \mathrm{~mm}, 5 \mu \mathrm{m}$, YMC Waters, Lisbon, Portugal). Tocopherol identification was made by comparing the relative retention times of sample peaks with standards and quantification was made by using the IS (tocol) method. Tocopherol contents in mycelium samples were expressed in $\mu \mathrm{g} \mathrm{g}^{-1}$ of dry weight.

\section{Evaluation of the antioxidant activity}

The tocopherol extracts were re-dissolved in methanol to obtain a stock solution of $10 \mathrm{mg} \mathrm{mL} \mathrm{mL}^{-1}$. DPPH scavenging activity and the reducing power assay were evaluated following previously reported procedures. ${ }^{17}$ Trolox was used as the standard.

\section{Incorporation of tocopherol extracts in natural yogurts}

General. The tested natural yogurts were purchased from a local market, in order to use commercial products wellaccepted by consumers. Five groups of yogurts (with $50 \mathrm{~g}$ each) were prepared: (i) control samples (yogurts without additives); (ii) yogurts with synthetic $\alpha$-tocopherol; (iii), (iv) and (v) samples with tocopherol-rich extracts from P. eryngii mycelia, $P$. ostreatus mycelia and G. lucidum mycelia, respectively. In the 
case of yogurts supplemented with mycelium extracts, the extract was added at a concentration corresponding to the $\mathrm{EC}_{50}$ obtained in the reducing power assay; on the other hand, synthetic $\alpha$-tocopherol was added at concentrations typically employed in similar food products. Two storage times were tested: 0 days (immediately after the incorporation) and after 7 days of storage at $4{ }^{\circ} \mathrm{C}$. Samples were lyophilized and tested for the tocopherol content and the maintenance of nutritional properties and antioxidant potential.

Nutritional composition of fortified yogurts. All samples were analyzed for the proximate composition (moisture, protein, fat, ash and carbohydrates) based on AOAC procedures. $^{27}$ The Kjeldahl method was performed to determine the crude protein content $(\mathrm{N} \times 6.38)$; Soxhlet apparatus was used to determine crude fat, by extracting a known weight of the powdered sample with petroleum ether; incineration at $600 \pm 15^{\circ} \mathrm{C}$ was performed to obtain the ash content; and total carbohydrates were calculated by difference. Energy was calculated according to the Regulation (EC) no. 1169/2011 of the European Parliament and of the Council of 25 October 2011, on the provision of food information to consumers, following the equation: Energy (kcal per $100 \mathrm{~g} \mathrm{dw})=4 \times(\mathrm{g}$ protein $+\mathrm{g}$ carbohydrates $)+9 \times(\mathrm{g}$ fat $)$.

Free sugars. Free sugars were extracted and analyzed by HPLC coupled to a refraction index detector (HPLC-RI, Smartline pump 1000, Knauer, Germany) using a previously described methodology (Reis et al., 2012). ${ }^{11}$ Sugars were identified by comparing the relative retention times of commercial standards with the sample peaks and quantification was made by the internal standard method. The results were expressed in $\mathrm{g}$ per $100 \mathrm{~g}$ of dry weight (dw).

Fatty acids. Fatty acids were extracted and analyzed by gas chromatography coupled to a flame ionization detector (GC-FID, DANI 1000, Contone, Switzerland) using a previously described methodology (Reis et al., 2012). ${ }^{11}$ Fatty acid methyl esters (FAMEs) were identified by comparing the relative retention times of commercial standards with the sample peaks and quantification was performed using the Clarity 4.0.1.7 Software (DataApex), with the results expressed as relative percentages of each fatty acid.

Statistical analysis. The employed statistical tests were done considering a 5\% significance level performed at a significance level (IBM SPSS Statistics for Windows, v. 22.0., IBM Corp., Armonk, NY, USA). The results (indicated as mean \pm standard deviation) were presented with different magnitudes, depending on the number of decimal places of the standard deviation. Two different comparison tests were performed: regarding the antioxidant activity of mycelia and the prepared yogurts, an analysis of variance (ANOVA) including the Tukey's test (homoscedastic distributions) or Tamhane's T2 test (heteroscedastic distributions) was applied; in the case of $\alpha$-tocopherol, and because there were less than three group levels, a simple $t$-student test was applied. Before ANOVA tests, the normal distribution of the residuals (verified by Shapiro Wilks' test) and the homogeneity of variance (checked by Levene's test) were assessed. In addition, the general linear model (GLM) pro- cedure (considering type III sums of squares) was employed to compare the nutritional parameters evaluated in yogurts. The factors defined in this 2-way ANOVA were "yogurt formulation" (YF) and "storage time" (ST), which were compared using Tukey's multiple comparison test in all cases where the interaction among factors was not significant. On the other hand, when the interaction among factors was significant, results were studied by evaluating the estimated marginal means plots for all levels of each factor.

The effect of YF was additionally evaluated through a linear discriminant analysis (LDA), performed according to the stepwise technique and considering the Wilks' $\lambda$ test to select variables (the $F$ value to enter: 3.84 ; the $F$ value to remove: 2.71 ). The main purpose was to estimate the association among single categorical dependent variables (YF) and quantitative independent variables (results from the laboratorial assays). The LDA outputs identified the independent variables with the highest contribution to differentiate the average score profiles of each YF. A leaving-one-out cross validation procedure was employed to validate the model performance.

\section{Results and discussion}

\section{Mycelium characterization}

In a previous study, our research group evaluated the effects of incorporating hydrophilic extracts (decoctions of Matricaria recutita L. and Foeniculum vulgare Mill.) in the overall quality of yogurt. ${ }^{15}$

In the present study, it was intended to evaluate the potentially positive effects of incorporating lipophilic antioxidants (specifically tocopherols) in the same food matrix, which has been tested in several fortification assays, owing to its high dissemination worldwide and consumption patterns. ${ }^{28-31}$

As a first step, the antioxidant potential of each mushroom mycelium alone was evaluated by performing DPPH scavenging activity and reducing power assays (Table 1). Despite the similarity between the three mushroom species, especially concerning the higher reducing power in comparison with the scavenging activity, the G. lucidum mycelium showed higher activity in both assays (DPPH scavenging activity: $\mathrm{EC}_{50}=10.4 \pm$ $0.2 \mathrm{mg} \mathrm{mL}{ }^{-1}$; reducing power: $\mathrm{EC}_{50}=0.32 \pm 0.01 \mathrm{mg} \mathrm{mL}^{-1}$ ).

Considering that it was intended to specifically fortify yogurt with vitamin E, the tocopherol profiles of mycelia were also characterized (Table 1). The first result to be highlighted is the dissimilarity with the profiles of the corresponding fruiting bodies. ${ }^{11}$ In fact, the mycelia of $P$. eryngii and $P$. ostreatus present a tocopherol profile with a high prevalence $(97 \%$ and $99 \%$, respectively) of $\beta$-tocopherol, while the tocopherol profile of the G. lucidum mycelium was particularly rich in $\delta$-tocopherol and $\beta$-tocopherol, different from the fruiting body, where $\alpha$-tocopherol and $\beta$-tocopherol were the only detected forms. ${ }^{32}$

Independently of qualitative differences, the mycelia of all mushrooms might be considered as potential sources of these lipophilic antioxidants, as indicated by the total tocopherol 


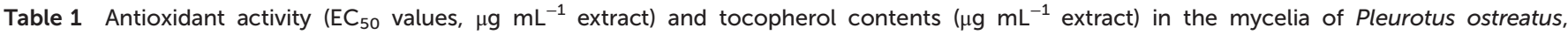
Pleurotus eryngii and Ganoderma lucidum. Values are given as mean \pm standard deviation

\begin{tabular}{|c|c|c|c|c|c|c|c|}
\hline & $\begin{array}{l}\text { DPPH scavenging } \\
\text { activity }\end{array}$ & $\begin{array}{l}\text { Reducing } \\
\text { power }\end{array}$ & $\alpha$-Tocopherol & $\beta$-Tocopherol & $\gamma$-Tocopherol & $\delta$-Tocopherol & Tocopherols \\
\hline Pleurotus ostreatus & $13.2 \pm 0.1 \mathrm{~b}$ & $0.63 \pm 0.01 \mathrm{a}$ & $17.5 \pm 0.5 \mathrm{a}$ & $664 \pm 7 \mathrm{a}$ & nd & $6.1 \pm 0.2 \mathrm{~b}$ & $687 \pm 7 \mathrm{~b}$ \\
\hline Pleurotus eryngii & $14.2 \pm 0.3 \mathrm{a}$ & $0.56 \pm 0.01 \mathrm{~b}$ & $0.6 \pm 0.1 \mathrm{c}$ & $468 \pm 6 \mathrm{~b}$ & $1.8 \pm 0.1$ & $2.1 \pm 0.1 \mathrm{~b}$ & $473 \pm 6 c$ \\
\hline$p$-Value $\left(n \quad\right.$ Homoscedasticity ${ }^{a}$ & $<0.001$ & 0.807 & $<0.001$ & 0.594 & $<0.001$ & $<0.001$ & 0.075 \\
\hline 1-Way ANOVA ${ }^{b}$ & $<0.001$ & $<0.001$ & $<0.001$ & $<0.001$ & $<0.001$ & $<0.001$ & $<0.001$ \\
\hline
\end{tabular}

${ }^{a}$ Homoscedasticity among mushroom species was tested by Levene's test: homoscedasticity, $p>0.050$; heteroscedasticity, $p<0.050 .{ }^{b}$ In the case of $\gamma$-tocopherol, a Student's $t$-test was applied, since there were less than three groups; in all cases, $p<0.050$ indicates that the mean value of at least one mushroom species is significantly different.

contents quantified in P. eryngii ( $473 \mu \mathrm{g}$ of tocopherols per $\mathrm{mL}$ of extract), P. ostreatus (687 $\mu \mathrm{g}$ of tocopherols per $\mathrm{mL}$ of extract) and G. lucidum (718 $\pm 12 \mu \mathrm{g}$ tocopherols per g extract).

\section{Characterization of differently fortified yogurts}

Besides comparing the effects of the incorporating agent among yogurt formulations, the influence of storage time (ST) was also evaluated by performing the assays in the preparation day and after 7 days of storage.

In order to understand the true effect of each factor (YF and $\mathrm{ST})$, their interaction $(\mathrm{YF} \times \mathrm{ST})$ was also evaluated to assess the possible cooperative effects (i.e., if the effect of ST over a determined parameter varied with the functionalizing agent and vice versa). In all cases where a significant interaction was found $(p<0.050)$, the multiple comparisons could not be performed. In those cases, some overall trends were tentatively obtained from the corresponding estimated marginal means (EMM) plots.

Regarding the nutritional composition (Table 2), the interaction among the factors was significant for fat, protein, lactose and energy, indicating that the effects of ST over these parameters varied with YF. Considering each factor individually, YF had a significant effect in all cases except the moisture content $(p=0.059)$, while ST only induced significant changes in lactose $(p=0.028)$ and energy $(p=0.004)$, both showing higher values in stored samples. Therefore, the statistical classification could only be indicated for the YF effect on ash (lowest in P. ostreatus) and carbohydrate (highest in P. ostreatus and $P$. eryngii) contents. Regarding other nutritional parameters, yogurts added with $P$. ostreatus mycelia tended to present lower fat and protein contents and energy levels, while yogurts prepared with the G. lucidum mycelium extract (together with the control) or commercial $\alpha$-tocopherol showed the highest fat and protein contents, respectively. In general, the proximate composition of studied yogurts was similar to that characterized in previous studies. ${ }^{15}$

The fatty acid profile of all prepared yogurts was also assayed, since these molecules are reliable indicators of adequate conservation processes. ${ }^{33}$ In addition to the tabled fatty acids (Table 3), C11:0, C13:0, C17:0, C20:0, C20:3n6, C20:4n6, C20:3n3 + C21:0, C20:5n3, C22:0, C23:0 and C24:0 were also quantified, but in relative percentages lower than $0.5 \%$ (nevertheless, all fatty acids were included in the linear discriminant analysis discussed in the next section). As it might be concluded from Table 3, the interaction among YF and ST was significant in most cases, except C10:0, C12:0, C14:0, C14:1 and C15:0. In contrast, YF caused significant changes in C6:0, C8:0, C12:0, C15:0, C16:0, C16:1, C18:0, C18:1n9, C18:2n6, and C18:3n3, and in MUFA and PUFA groups, while ST produced a

Table 2 Nutritional composition (g per $100 \mathrm{~g} \mathrm{fw}$ ) and energy (kcal per $100 \mathrm{~g} \mathrm{fw}$ ) values for different yogurt formulations (YF) and storage times (ST). Results are presented as mean \pm standard deviation $^{a}$

\begin{tabular}{|c|c|c|c|c|c|c|c|c|}
\hline & & Moisture & Fat & Protein & Ash & Carbohydrates & Lactose & Energy \\
\hline \multirow[t]{6}{*}{ YF } & Control & $85 \pm 1$ & $3.7 \pm 0.3$ & $4.7 \pm 0.2$ & $0.88 \pm 0.04 \mathrm{ab}$ & $5.7 \pm 0.2 \mathrm{~b}$ & $4.0 \pm 0.3$ & $75 \pm 2$ \\
\hline & $\alpha$-Tocopherol & $85 \pm 1$ & $3.5 \pm 0.2$ & $4.9 \pm 0.2$ & $0.86 \pm 0.05 a b c$ & $5.8 \pm 0.2 \mathrm{ab}$ & $3.6 \pm 0.5$ & $75 \pm 1$ \\
\hline & P. ostreatus & $86 \pm 1$ & $3.3 \pm 0.2$ & $4.4 \pm 0.1$ & $0.83 \pm 0.03 \mathrm{c}$ & $6.0 \pm 0.2 \mathrm{a}$ & $4.1 \pm 0.2$ & $71 \pm 1$ \\
\hline & P. eryngii & $85 \pm 1$ & $3.6 \pm 0.2$ & $4.6 \pm 0.2$ & $0.84 \pm 0.04 \mathrm{bc}$ & $6.0 \pm 0.2 \mathrm{a}$ & $4.3 \pm 0.4$ & $75 \pm 2$ \\
\hline & G. lucidum & $85 \pm 1$ & $3.7 \pm 0.2$ & $4.7 \pm 0.2$ & $0.88 \pm 0.04 \mathrm{ab}$ & $5.8 \pm 0.2 \mathrm{~b}$ & $4.1 \pm 0.2$ & $75 \pm 2$ \\
\hline & ANOVA $p$-value $(n=18)^{b}$ & 0.059 & $<0.001$ & $<0.001$ & 0.001 & $<0.001$ & $<0.001$ & $<0.001$ \\
\hline \multirow[t]{3}{*}{ ST } & 0 days & $85 \pm 1$ & $3.5 \pm 0.2$ & $4.7 \pm 0.2$ & $0.85 \pm 0.04$ & $5.8 \pm 0.2$ & $3.9 \pm 0.5$ & $73 \pm 2$ \\
\hline & 7 days & $85 \pm 1$ & $3.6 \pm 0.3$ & $4.6 \pm 0.3$ & $0.86 \pm 0.05$ & $5.8 \pm 0.3$ & $4.1 \pm 0.2$ & $75 \pm 2$ \\
\hline & ANOVA $p$-value $(n=45)^{c}$ & 0.142 & 0.101 & 0.249 & 0.149 & 0.746 & 0.028 & 0.004 \\
\hline $\mathrm{YF} \times \mathrm{ST}$ & $p$-Value $(n=90)^{d}$ & 0.701 & 0.002 & $<0.001$ & 0.190 & 0.350 & $<0.001$ & 0.004 \\
\hline
\end{tabular}

${ }^{a}$ Results are reported as mean values of the yogurt formulation (YF), including results from 0 and 7 days, and mean values of each storage time (ST), considering all YF in each period. ${ }^{b}$ If $p<0.050$, the corresponding parameter presented a significantly different value for at least one YF. ${ }^{c}$ If $p<0.050$, the corresponding parameter presented a significantly different value among both ST. ${ }^{d}$ If $p<0.050$, the interaction among factors is significant; in this case, no multiple comparisons can be performed. 


\begin{tabular}{|c|c|c|c|c|c|c|c|c|c|c|c|c|c|c|c|c|c|c|}
\hline & & $\mathrm{C} 4: 0$ & C6:0 & C8:0 & C10:0 & C12:0 & C14:0 & C14:1 & C15:0 & C16:0 & C16:1 & C18:0 & C18:1n9 & C18:2n6 & C18:3n3 & SFA & MUFA & PUFA \\
\hline \multirow[t]{6}{*}{ YF } & Control & $3.6 \pm 0.4$ & $2.8 \pm 0.3$ & $1.5 \pm 0.1$ & $3.0 \pm 0.2$ & $3.5 \pm 0.2 \mathrm{ab}$ & $11.2 \pm 0.3$ & $0.8 \pm 0.1$ & $1.4 \pm 0.1 \mathrm{ab}$ & $31 \pm 1$ & $1.4 \pm 0.1$ & $10.9 \pm 0.3$ & $24 \pm 1$ & $2.4 \pm 0.2$ & $1.6 \pm 0.1$ & $70 \pm 1$ & $26 \pm 1$ & $4.3 \pm 0.2$ \\
\hline & $\alpha$-Tocopherol & $3.8 \pm 0.1$ & $2.8 \pm 0.2$ & $1.5 \pm 0.1$ & $3.0 \pm 0.1$ & $3.5 \pm 0.2 \mathrm{ab}$ & $11.2 \pm 0.2$ & $0.8 \pm 0.1$ & $1.4 \pm 0.1 \mathrm{ab}$ & $31 \pm 1$ & $1.4 \pm 0.1$ & $11.2 \pm 0.4$ & $24 \pm 1$ & $2.1 \pm 0.2$ & $1.2 \pm 0.2$ & $71 \pm 1$ & $26 \pm 1$ & $3.5 \pm 0.4$ \\
\hline & P. ostreatus & $3.8 \pm 0.3$ & $2.9 \pm 0.3$ & $1.5 \pm 0.1$ & $3.1 \pm 0.2$ & $3.6 \pm 0.2 \mathrm{a}$ & $11.3 \pm 0.4$ & $0.8 \pm 0.1$ & $1.4 \pm 0.1 \mathrm{a}$ & $32 \pm 1$ & $1.4 \pm 0.1$ & $10.1 \pm 0.3$ & $22 \pm 1$ & $2.8 \pm 0.2$ & $1.6 \pm 0.1$ & $71 \pm 1$ & $24 \pm 1$ & $4.8 \pm 0.2$ \\
\hline & P. eryngii & $3.8 \pm 0.5$ & $3.1 \pm 0.5$ & $1.5 \pm 0.2$ & $3.0 \pm 0.2$ & $3.4 \pm 0.1 \mathrm{~b}$ & $11.1 \pm 0.2$ & $0.8 \pm 0.1$ & $1.3 \pm 0.1 \mathrm{~b}$ & $31 \pm 1$ & $1.3 \pm 0.1$ & $10.4 \pm 0.3$ & $23 \pm 1$ & $2.5 \pm 0.1$ & $1.6 \pm 0.1$ & $70 \pm 1$ & $25 \pm 1$ & $4.5 \pm 0.1$ \\
\hline & G. lucidum & $3.6 \pm 0.5$ & $2.6 \pm 0.2$ & $1.4 \pm 0.1$ & $3.0 \pm 0.1$ & $3.4 \pm 0.2 \mathrm{~b}$ & $11.2 \pm 0.3$ & $0.8 \pm 0.1$ & $1.4 \pm 0.1 \mathrm{ab}$ & $31 \pm 1$ & $1.3 \pm 0.1$ & $10.9 \pm 0.4$ & $24 \pm 1$ & $2.5 \pm 0.2$ & $1.6 \pm 0.1$ & $70 \pm 1$ & $26 \pm 1$ & $4.4 \pm 0.2$ \\
\hline & $\begin{array}{l}\text { ANOVA } p \text {-value } \\
(n=18)^{b}\end{array}$ & 0.352 & $<0.001$ & 0.006 & 0.142 & 0.008 & 0.294 & 0.598 & 0.021 & $<0.001$ & 0.025 & $<0.001$ & $<0.001$ & $<0.001$ & $<0.001$ & 0.068 & $<0.001$ & $<0.001$ \\
\hline \multirow[t]{3}{*}{ ST } & 0 days & $3.5 \pm 0.5$ & $2.7 \pm 0.5$ & $1.4 \pm 0.1$ & $3.0 \pm 0.1$ & $3.4 \pm 0.2$ & $11.2 \pm 0.3$ & $0.8 \pm 0.1$ & $1.4 \pm 0.1$ & $31 \pm 1$ & $1.3 \pm 0.1$ & $10.8 \pm 0.5$ & $23 \pm 1$ & $2.5 \pm 0.3$ & $1.5 \pm 0.2$ & $70 \pm 1$ & $25 \pm 1$ & $4.3 \pm 0.5$ \\
\hline & 7 days & $3.9 \pm 0.3$ & $2.9 \pm 0.2$ & $1.5 \pm 0.1$ & $3.1 \pm 0.2$ & $3.5 \pm 0.2$ & $11.2 \pm 0.3$ & $0.8 \pm 0.1$ & $1.4 \pm 0.1$ & $30 \pm 1$ & $1.3 \pm 0.1$ & $10.7 \pm 0.5$ & $23 \pm 1$ & $2.4 \pm 0.2$ & $1.5 \pm 0.1$ & $70 \pm 1$ & $25 \pm 1$ & $4.3 \pm 0.3$ \\
\hline & $\begin{array}{l}\text { ANOVA } p \text {-value } \\
(n=45)^{c}\end{array}$ & $<0.001$ & 0.027 & $<0.001$ & 0.001 & 0.092 & 0.847 & 0.899 & 0.810 & 0.017 & 0.745 & 0.440 & 0.343 & 0.191 & 0.224 & 0.296 & 0.323 & 0.870 \\
\hline $\mathrm{YF} \times \mathrm{ST}$ & $\begin{array}{l}p \text {-Value } \\
(n=90)^{d}\end{array}$ & $<0.001$ & $<0.001$ & 0.002 & 0.066 & 0.412 & 0.598 & 0.080 & 0.159 & 0.040 & $<0.001$ & $<0.001$ & $<0.001$ & $<0.001$ & $<0.001$ & $<0.001$ & $<0.001$ & $<0.001$ \\
\hline
\end{tabular}

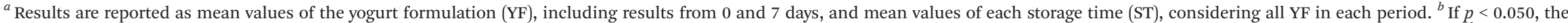

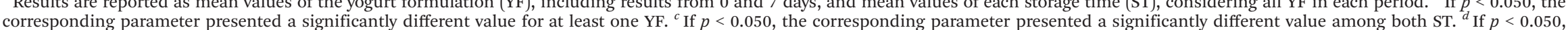

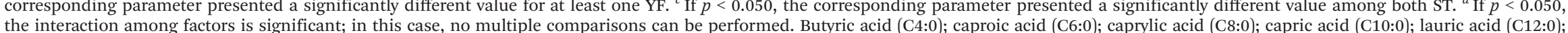

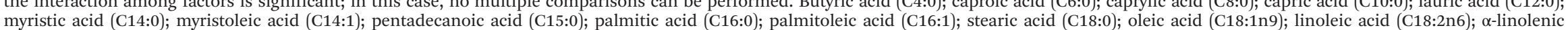
myristic acid (C14:0); myristoleic acid (C14:1); pentadecanoic acid (C15:0); palmitic acid (C16:0); palmitoleic acid (C16
acid (C18:3n3). SFA - saturated fatty acids; MUFA - monounsaturated fatty acids; PUFA - polyunsaturated fatty acids.
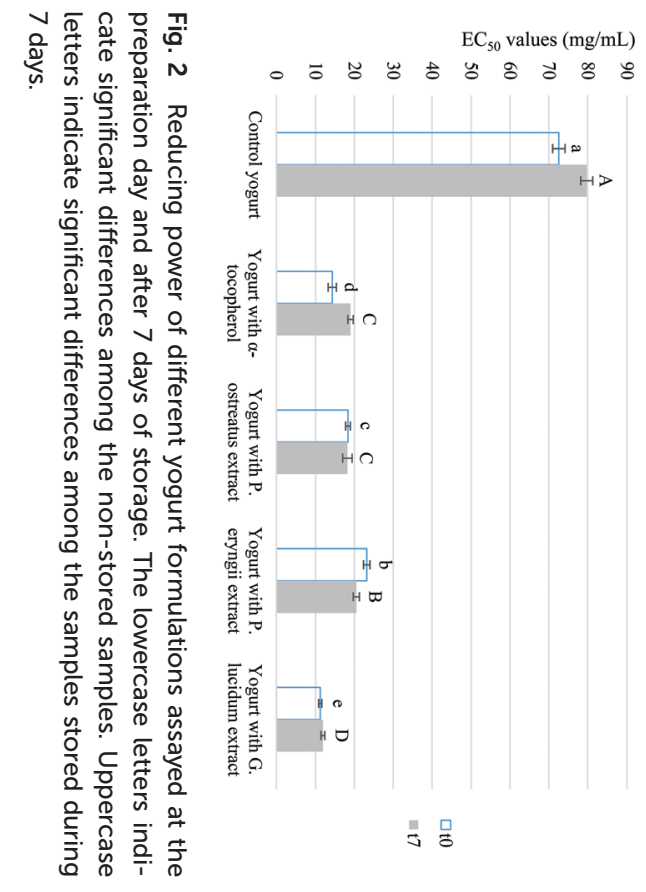

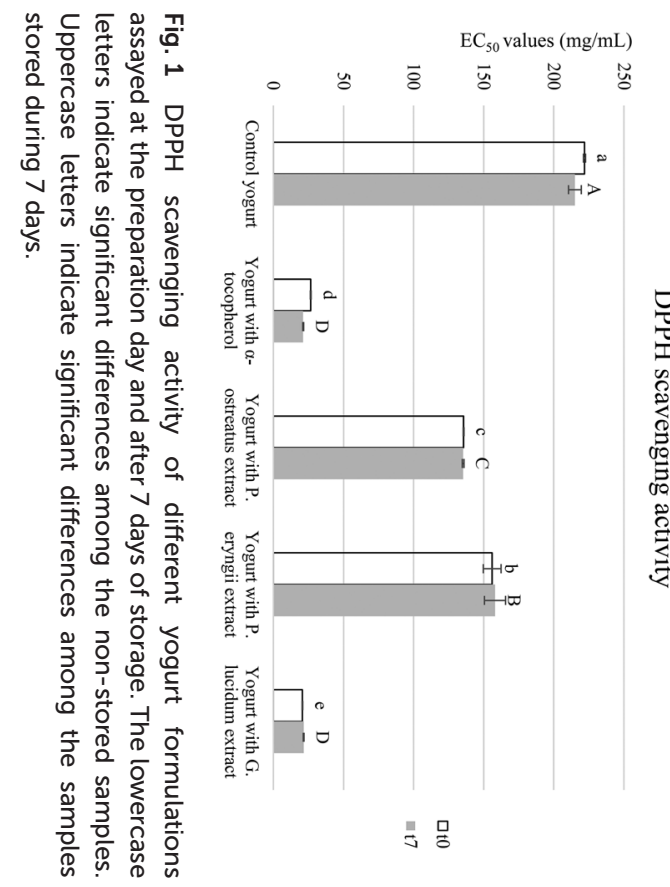



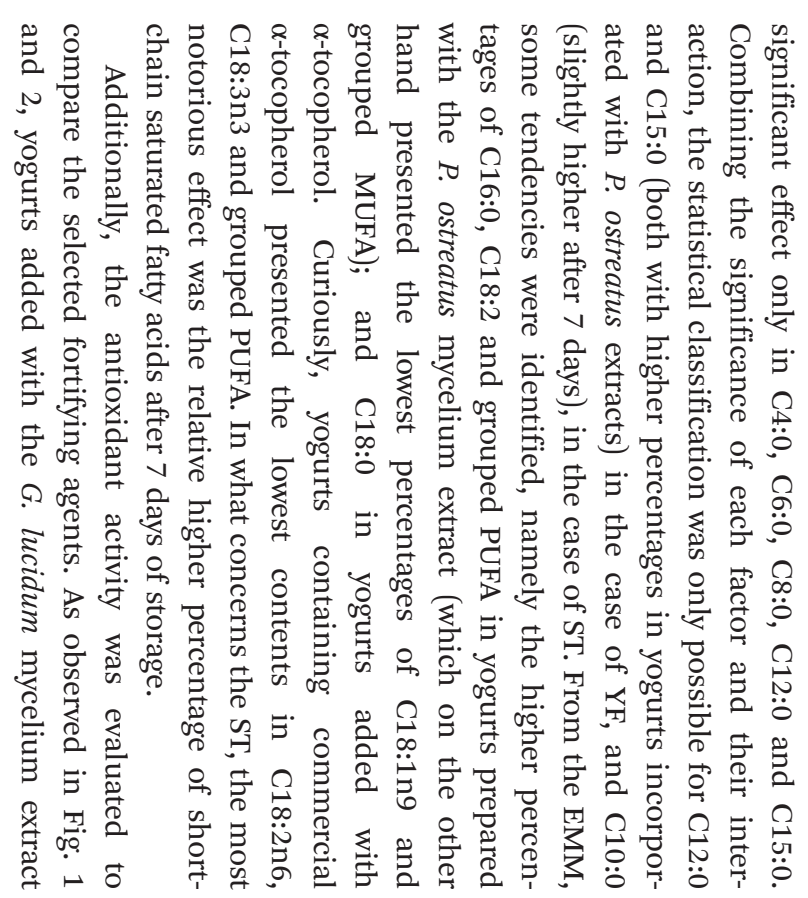


gave significantly stronger DPPH scavenging activity and reducing power, either in non-stored samples or in those stored during 7 days. The higher activity verified among G. lucidum might also be related to other bioactivities attributed to this mushroom, which is mostly known for its immunomodulatory properties. In fact, the oxidative stress status modulates the production of compounds of the immune system, being possible that the consumption of these molecules reestablishes the antioxidative status, boosting the immunity without the risk of oxidative stress. ${ }^{34,35}$

The second best results were obtained with yogurts added with commercial $\alpha$-tocopherol, followed by those incorporating $P$. ostreatus and P. eryngii extracts. In either case, all functionalized formulations presented significantly higher antioxidant activity than that of the corresponding controls. In the same graphs, it is also possible to observe the similarity of results among both assayed periods, which is a good indicator of the stability of both types of antioxidant activity. It is also noteworthy that the $\mathrm{EC}_{50}$ values obtained in the reducing power assay were lower than those obtained in the DPPH scavenging activity assay (in all samples).

\section{Linear discriminant analysis}

In the former section, some statistically significant differences were found in specific parameters, mainly resulting from changes induced by YF. Complementarily, besides identifying individual changes, it would be interesting to find the parameters that typify each YF, namely by evaluating changes in all parameters simultaneously. With this purpose, a linear discriminant analysis (LDA) was performed to evaluate the correlations among YF (categorical dependent variables) and the matrix of the obtained results (quantitative independent variables). The significant independent variables were selected following the stepwise method, as validated by the Wilks' $\lambda$ test. Only variables with a statistically significant classification performance $(p<0.050)$ were maintained by the statistical model.

The first three defined discriminant functions included 99.6\% (first function: $85.9 \%$; second function: $13.0 \%$; third function: $0.7 \%$ ) of the observed variance (Fig. 3). From the 37 variables included in the analysis, the model selected protein, energy, C11:0, C18:0, C18:1n9, C18:2n6, C20:0, C20:3n6, C20:4n6, C20:5n3, C22:0, and C23:0, DPPH scavenging activity and reducing power as those with the highest discriminant effect, indicating that the most relevant changes occurred mainly in fatty acids and antioxidant activity.

Considering the correlations among the functions and variables, function 1 was highly correlated with reducing power, effectively separating markers corresponding to control yogurts, owing to their lower activity (higher $\mathrm{EC}_{50}$ values), from all other formulations. Function 2, which was more highly correlated to DPPH scavenging activity, separated markers corresponding to yogurts prepared with $\alpha$-tocopherol and G. lucidum (lower $\mathrm{EC}_{50}$ values, being therefore placed in the negative side of the axis) from those prepared with $P$. eryngii and P. ostreatus (higher $\mathrm{EC}_{50}$ values, being therefore distributed in the positive side of the axis). Finally, function 3 was more highly correlated

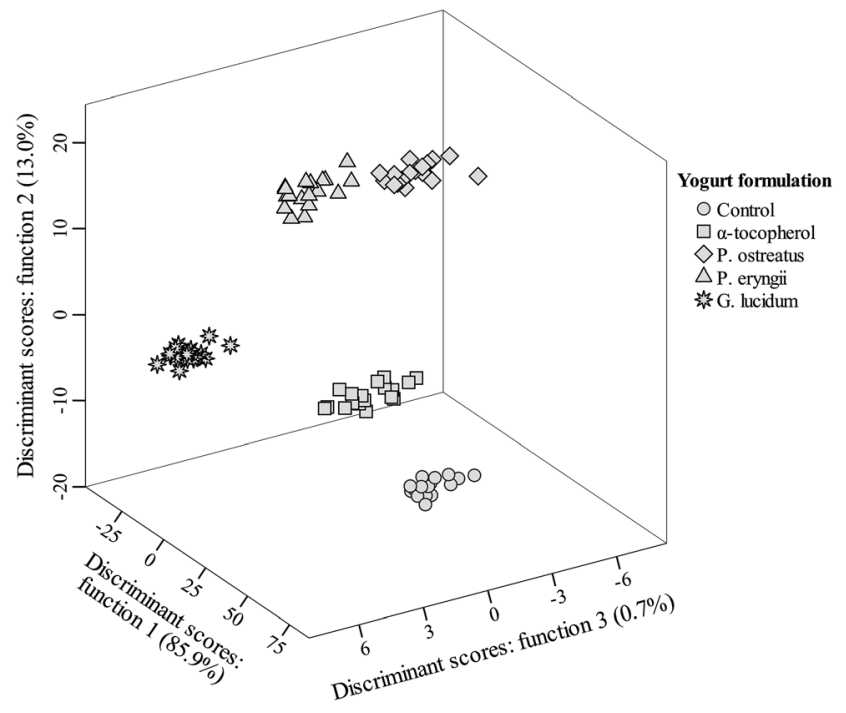

Fig. 3 Canonical discriminant function coefficients defined from the evaluated parameters to assess the overall effects of yogurt formulation.

with C18:1n9, but it did not have a significant contribution in separating YF markers, in line with the low percentage of the included variance $(0.7 \%)$. The classification performance was $100 \%$ accurate for original grouped cases and for cross-validated grouped cases.

In conclusion, the mycelia of the selected mushroom species proved to be effective choices as sources of lipophilic antioxidants to be employed in yogurt fortification, as validated by the similar antioxidant activities obtained in the corresponding YF. Nevertheless, the G. lucidum mycelium should be highlighted as the case study with the highest potential, owing to its higher DPPH scavenging activity and reducing power. This higher activity might probably be explained by the tocopherol profile of the G. lucidum mycelium when compared to those of $P$. eryngii and $P$. ostreatus (both presenting $\beta$-tocopherol as the highly prevalent tocopherol form).

In either case, the bioactivity results were highly satisfactory, particularly considering that the nutritional changes were nearly irrelevant (as indicated by the performed LDA).

\section{Conflicts of interest}

There are no conflicts to declare.

\section{Acknowledgements}

The authors are grateful to the Foundation for Science and Technology (FCT, Portugal) and FEDER under Programme PT2020 for financial support to CIMO (UID/AGR/00690/2013), L. Barros and J. Barreira contracts. This work is funded by the European Regional Development Fund (ERDF) through the Regional Operational Program North 2020, within the scope of 
Project NORTE-01-0145-FEDER-023289: DeCodE and Project Mobilizador Norte-01-0247-FEDER-024479: ValorNatural®.

\section{References}

1 M. Carocho, M. F. Barreiro, P. Morales and I. C. F. R. Ferreira, Compr. Rev. Food Sci. Food Saf., 2014, 13, 377399.

2 S. Randhawa and S. L. Bahna, Curr. Opin. Allergy Clin. Immunol., 2009, 9, 278-283.

3 M. Carocho, P. Morales and I. C. F. R. Ferreira, Trends Food Sci. Technol., 2015, 45, 284-295.

4 M. Carocho and I. C. F. R. Ferreira, Food Chem. Toxicol., 2013, 51, 15-25.

5 Joint FAO/WHO Expert Committee on Food Additives, World Health Organization and Food and Agriculture Organization of the United Nations, Toxicological evaluation of certain food additives and contaminants, 1993.

6 P. C. K. Cheung, Nutr. Bull., 2010, 35, 292-299.

7 I. C. F. R. Ferreira, L. Barros and R. M. V. Abreu, Curr. Med. Chem., 2009, 16, 1543-1560.

8 M. Öztürk, G. Tel-Çayan, A. Muhammad, P. Terziołlu and M. E. Duru, Stud. Nat. Prod. Chem., 2015, 45, 363-456.

9 S. Patel and A. Goyal, 3 Biotech, 2012, 2, 1-15.

10 M. Soković, A. Ćirić, J. Glamočlija and D. Stojković, in Wild Plants, Mushrooms and Nuts: Functional Food Properties and Applications, 2016, pp. 83-122.

11 F. S. Reis, L. Barros, A. Martins and I. C. F. R. Ferreira, Food Chem. Toxicol., 2012, 50, 191-197.

12 K. J. Heller, in American Journal of Clinical Nutrition, 2001, vol. 73.

13 K. Nakasaki, M. Yanagisawa and K. Kobayashi, J. Biosci. Bioeng., 2008, 105, 73-76.

14 M. Bertolino, S. Belviso, B. Dal Bello, D. Ghirardello, M. Giordano, L. Rolle, V. Gerbi and G. Zeppa, LWT - Food Sci. Technol., 2014, 63, 1145-1154.

15 C. Caleja, L. Barros, A. L. Antonio, M. Carocho, M. B. P. P. Oliveira and I. C. F. R. Ferreira, Food Chem., 2016, 210, 262-268.

16 Â. Fernandes, J. C. M. Barreira, A. L. Antonio, A. Martins, I. C. F. R. Ferreira and M. B. P. P. Oliveira, Food Chem., 2014, 159, 399-406.
17 S. A. Heleno, L. Barros, A. Martins, M. J. R. P. Queiroz, C. Santos-Buelga and I. C. F. R. Ferreira, Food Res. Int., 2012, 46, 135-140.

18 F. S. Reis, I. C. F. R. Ferreira, L. Barros and A. Martins, LWT - Food Sci. Technol., 2011, 44, 820-824.

19 Q.-Z. Cao and Z.-B. Lin, Acta Pharmacol. Sin., 2004, 25, 833838.

20 S. A. Heleno, I. C. F. R. Ferreira, A. P. Esteves, A. Ćirić, J. Glamočlija, A. Martins, M. Soković and M. J. R. P. Queiroz, Food Chem. Toxicol., 2013, 58, 95-100.

21 C. Xiao, Q. Wu, J. Zhang, Y. Xie, W. Cai and J. Tan, J. Ethnopharmacol., 2017, 196, 47-57.

22 D. Ren, N. Wang, J. Guo, L. Yuan and X. Yang, Carbohydr. Polym., 2016, 138, 123-133.

23 F. Souilem, Â. Fernandes, R. C. Calhelha, J. C. M. Barreira, L. Barros, F. Skhiri, A. Martins and I. C. F. R. Ferreira, Food Chem., 2017, 230, 40-48.

24 X. Liu, B. Zhou, R. Lin, L. Jia, P. Deng, K. Fan, G. Wang, L. Wang and J. Zhang, Int. J. Biol. Macromol., 2010, 47, 116119.

25 R. Kamble, S. Venkata and A. M. Gupte, J. Pure Appl. Microbiol., 2011, 5, 983-986.

26 S. A. Heleno, L. Barros, M. J. Sousa, A. Martins and I. C. F. R. Ferreira, Food Chem., 2010, 119, 1443-1450.

27 AOAC, Official Methods of Analysis of AOAC International, 20th edn, 2016.

28 T. Ghorbanzade, S. M. Jafari, S. Akhavan and R. Hadavi, Food Chem., 2017, 216, 146-152.

29 M. Karaaslan, M. Ozden, H. Vardin and H. Turkoglu, LWTFood Sci. Technol., 2011, 44, 1065-1072.

30 M. C. Karam, C. Gaiani, C. Hosri, J. Burgain and J. Scher, J. Dairy Res., 2013, 80, 400-409.

31 E. Santillán-Urquiza, M. Á. Méndez-Rojas and J. F. VélezRuiz, LWT - Food Sci. Technol., 2017, 80, 462-469.

32 D. S. Stojković, L. Barros, R. C. Calhelha, J. Glamočlija, A. Ćirić, L. J. L. D. van Griensven, M. Soković and I. C. F. R. Ferreira, Int. J. Food Sci. Nutr., 2014, 65, 42-47.

33 J. C. M. Barreira, J. A. Pereira, M. B. P. P. Oliveira and I. C. F. R. Ferreira, Plant Foods Hum. Nutr., 2010, 65, 38-43.

34 X. Jin, J. Ruiz Beguerie, D. M. Y. Sze and G. C. F. Chan, Cochrane Database Syst. Rev., 2016, 4, CD007731.

35 J. D. Biller-Takahashi, L. S. Takahashi, F. E. Mingatto and E. C. Urbinati, Fish Shellfish Immunol., 2015, 47, 360-367. 